\title{
PROPOSTA DE PLANO DE CLASSIFICAÇÃo FACETADO PARA AS UNIVERSIDADES FEDERAIS
}

\author{
PROPOSAL PLAN OF CLASSIFICATION FACETED \\ FOR FEDERAL UNIVERSITIES
}

PROPUESTA DE PLAN DE CLASSIFICACIÓN FACETADA

PARA UNIVERSIDADES FEDERALES

${ }^{1}$ Renata Santos Brandão ${ }^{1}$ Marcel Ferrante Silva

${ }^{1}$ Universidade Federal de Goiás

Correspondência

${ }^{1}$ Renata Santos Brandão

Universidade Federal de Goiás

Goiânia, GO - Brasil.

Email: marcelf@gmail.com

ORCID: http://orcid.org/0000-0002-3976-402X

Submetido em: 25/07/2017

Aceito em: 14/09/2017

Publicado em: 18/09/2017

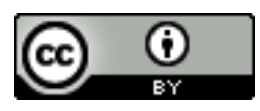

JITA: IC. Index languages, processes and schemes. 
RESUMO: O estudo tem como objetivo apresentar um plano de classificação facetado para a gestão arquivística de documentos nas universidades federais do Brasil. Para isso foi realizada um levantamento bibliográfico sobre a gestão arquivística no Brasil, os tipos de planos de classificação e a teoria da classificação facetada de Ranganathan, por meio de buscas em bases de dados nas áreas de Biblioteconomia e Arquivologia. Foi identificado o plano de classificação utilizado nas Instituições Federais de Ensino Superior para representar a faceta funcional e criado o plano de classificação estrutural para representar a faceta estrutural. Os dois planos de classificação foram inseridos em um sistema de gestão de repositório digital para dar origem ao plano de classificação facetado. O sistema utilizado foi o Tainacan, software livre baseado no wordpressusado na gestão de documentos digitais. O plano de classificação facetado desenvolvido permite ao usuário escolher e até combinar a forma de buscar a informação que garante uma maior eficiência na recuperação da informação.

PALAVRAS-ChaVE: Classificação facetada. Plano de classificação. Arquivologia. Gestão de documentos.

ABSTRACT: This study aims to present a faceted classification plan for the archival management of documents in the federal universities of Brazil. For this, was done a literature review on the archival management in Brazil, the types of classification plans and the theory of the Ranganathan faceted classification, through searches in databases in the areas of Librarianship and Archivology. It was identified the classification plan used in the Federal Institutions of Higher Education to represent the functional facet and created the structural classification plan to represent the structural facet. The two classification plans were inserted into a digital repository management system to give rise to the faceted classification plan. The system used was Tainacan, free software wordpress-based used in digital document management. The developed faceted classification plan allows the user to choose and even combine the way to look for the information that guarantees agreater efficiency in the information retrieval.

KEYWORDS: Faceted classification. Classification plan. Records management. Document managment.

RESUMEN:El presente estudio tiene como objetivo presentar un plan de clasificación facetado para la gestión archivística de documentos en las universidades federales de Brasil. Para ello se realizó un levantamiento bibliográfico sobre la gestión archivística en Brasil, los tipos de planes de clasificación y la teoría de la clasificación facetada de Ranganathan, por medio de búsquedas en bases de datos en las áreas de Biblioteconomía y Archivología. Se identificó el plan de clasificación utilizado en las Instituciones Federales de Enseñanza Superior para representar la faceta funcional y creado el plan de clasificación estructural para representar la faceta estructural. Los dos planes de clasificación se introdujeron en un sistema de gestión de repositorios digitales para dar lugar al plan de clasificación facetado. El sistema utilizado fue Tainacan, software libre basado en wordpress utilizado en la gestión de documentos digitales. El plan de clasificación facetado desarrollado permite al usuario elegir e incluso combinar la forma de buscar la información que garantiza una mayor eficiencia en la recuperación de la información.

Palabrasclave: Clasificación facetada. Plan de clasificación.Gestión de archivos.Gestión de documentos. 


\section{INTRODUÇÃ̃o}

Um documento arquivístico é qualquer documento produzido que contenha informação que comprove a realização de uma atividade e sirva de evidência da mesma, independente de como, quando ou do material em que foi registrada.

Os documentos constituem provas, e devem ser tratados como um patrimônio da empresa, pois ele poderá, oportunamente, definir questões vitais da organização, ou ainda salvá-la de prejuízos, devido a não comprovação de documentos legais ou fiscais (SABINO; ROCHA, 2004, p. 85).

Segundo Paes (2002), a principal finalidade de um documento arquivístico é servir à administração, constituindo-se, com o decorrer do tempo, em base do conhecimento e memória organizacional. Entretanto, no cenário atual é notório o fluxo constante e gradativo das informações no formato digital. As transformações causadas pelas tecnologias da informação e comunicação e a digitalização de documentos trazem desafios a recuperação da informação devido ao crescente volume e variedade de formatos.

Em um sistema de recuperação da informação, o usuário visa encontrar um documento ou documentos que vão atender as suas necessidades de informação, assim a recuperação da informação será a consequência do ato de busca. Choo (2003) conceitua a busca da informação em três estágios: a necessidade, a busca e o uso da informação. Assim, a busca da informação é o momento no qual a informação torna-se útil para o indivíduo que, consequentemente, altera o seu estado de conhecimento.

Segundo Rouse e Rouse (1984, p.129), o ser humano raramente busca a informação como um fim de si mesma, isso significa que a busca faz parte de um processo cognitivo no qual o indivíduo transpõe seu estado de conhecimento atual. A utilização da informação, seja para a tomada de decisão, solução de problemas ou alocação de recursos, depende da sua recuperação, principalmente quando se trata de informação no formato digital.

A recuperação da informação está intimamente relacionada à organização dos documentos. Segundo a Lei Federal $n^{\circ} 8.159$, que se refere aos arquivos públicos e privados constituídos por pessoas físicas ou jurídicas, a gestão arquivística de documentos é definida como "o conjunto de procedimentos e operações técnicas referentes à sua produção, tramitação, uso, avaliação e arquivamento em fase corrente e intermediária, visando a sua eliminação ou recolhimento para guarda permanente" (BRASIL, 1991).

Na gestão arquivística de documentos são realizadas a atividades de classificação, avaliação e descrição dos documentos auxiliando no acesso à informação. Assim, são utilizadas técnicas e procedimentos da arquivologia para realizar a organização dos documentos contribuindo para a sua recuperação. O plano de classificação e a tabela de temporalidade são ferramentas essências para a gestão arquivística.

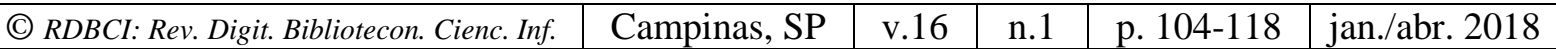


Entende-se por classificação de documentos: "sequência de procedimentos e operações técnicas que visam a agrupar os documentos de arquivo relacionando-os ao órgão produtor, à função, à subfunção e atividade responsável por sua produção ou acumulação"(SÃO PAULO, 2004, art.10).

O instrumento resultante da classificação é o plano de classificação que tem como objetivo agrupar os documentos a partir de características em comum, organizados sistematicamente, e utilizando códigos de identificação. Conforme Camargo e Belloto (1996), o plano de classificação é um esquema pelo qual se processa a classificação de um arquivo. Uma outra definição de plano de classificação é:

Esquema de distribuição de documentos em classes, de acordo com métodos de arquivamento específicos, elaborados a partir do estudo das estruturas e funções de uma instituição e da análise do arquivo por ela produzido. Expressão geralmente adotada em arquivos correntes (ARQUIVO NACIONAL, 2005, p. 132).

O plano de classificação se constitui na principal atividade da gestão de documentos de uso corrente e agrupa os documentos em classes, organizados de acordo com um critério que pode ser de dois tipos: funcional ou estrutural.

A classificação do tipo estrutural se baseia na estrutura administrativa da entidade para organizar o acervo e devido a isso é facilmente implementada. Segundo Schellenberg (2005), essa classificação não é a mais adequada, pois as estruturas organizacionais das entidades são voláteis e com mudanças que nem sempre resultam de uma análise funcional, mas de desdobramentos políticos que acabam inviabilizando a utilização da classificação estrutural. Nessa organização, a classificação dos documentos acompanha a estrutura da entidade, assim se a atividade de um departamento for transferida para outro ou se um novo departamento for criado e suas atribuições forem redistribuídas, todos os documentos devem ser reclassificados.

A classificação do tipo funcional se baseia na função da entidade e não com sua a estrutura, e se preocupa com a contextualização dos documentos. A função do documento é definida a partir da observação de como documento foi gerado e de que maneira se dá o seu trâmite.Esse tipo de classificação é considerado mais robusto e resistente a mudanças estruturais, pois mesmo com a fusão ou divisão de um departamento, as atividades geralmente são preservadas, impactando menos na classificação dos documentos. O quadro abaixo apresenta as etapas e elementos necessários para a construção de um plano de classificação do tipo funcional: 
Quadro 1. Etapas e elementos para a construção de um plano de classificação funcional

\begin{tabular}{|c|c|}
\hline ETAPAS & ELEMENTOS \\
\hline 1- Fatores a considerar & $\begin{array}{l}\text { - Existência de legislação arquivística e } \\
\text { - Princípios que regem a construção de linguagens } \\
\text { documentárias }\end{array}$ \\
\hline 2-Contextualização & $\begin{array}{l}\text { - Denominação (nome e sigla), localização, área de } \\
\text { atuação, criação e vinculação administrativa e } \\
\text { política }\end{array}$ \\
\hline 3 - Estrutura organizacional & $\begin{array}{l}\text { - Organograma, atribuições, unidades } \\
\text { organizacionais da atividade-meio e da atividade- } \\
\text { fim e alteraçōes e modificaçōes }\end{array}$ \\
\hline 4- Unidade organizacional & $\begin{array}{l}\text { - Denominação, localização, responsáveis, } \\
\text { vinculação hierárquica }\end{array}$ \\
\hline 5- Atribuição & $\begin{array}{l}\text { - Descrição das atividades que compõem a } \\
\text { atribuição }\end{array}$ \\
\hline 6- Atividade & - Descrição das tarefas que compõem a atividade \\
\hline 7-Tarefa & $\begin{array}{l}\text { - Identificação dos tipos documentais que podem } \\
\text { ser resultado das tarefas executadas. }\end{array}$ \\
\hline 8- Validação técnica & $\begin{array}{l}\text { - Aplicável para áreas complexas, em termos } \\
\text { técnicos. }\end{array}$ \\
\hline
\end{tabular}

Fonte: Adaptado por Rios (2009, p. 95 citado porSOUSA, 2007, p. 149)

Apesar do plano de classificação funcional ser mais imune a mudanças, segundo Souza (2014), possui limitações na aplicação no dia-a-dia, pois a recuperação dos documentos pode se tornar lenta e ineficiente, principalmente nas fases corrente e intermediária, pela dificuldade de inserir no plano de classificação um documento que possua caráter interdisciplinar e também na abstração que o usuário tem que fazer para indicar a função ou atividade que o documento pertence.

A partir do plano de classificação é elaborada a tabela de temporalidade, que é outro um instrumento utilizado na gestão arquivística. A tabela de temporalidade define os prazos de guarda, nas fases corrente e intermediária, e destinação dos arquivos, visando garantir o acesso à informação. Segundo Paes (2002):

a tabela de temporalidade é o instrumento de destinação que determina os prazos em que os documentos devem ser mantidos nos arquivos correntes e/ou intermediários, ou recolhidos aos arquivos permanentes, estabelecendo critérios para microfilmagem e eliminação (PAES, 2002, p. 106).

A tabela de temporalidade é resultante do processo de avaliação documental, enquanto o plano de classificação é utilizado para classificar os documentos produzidos ou recebidos por uma entidade, ambos são instrumentos básicos na gestão arquivística que permitem a definição dos prazos de guarda e destinação, o armazenamento e a recuperação da informação contida nos arquivos.

O estabelecimento do tipo de organização do plano de classificação pode ser um fator limitante para o usuário. Uma organização definida, através de funções e atividades, no tipo funcional, ou através de setores e departamentos, no tipo estrutural, determina o modo como o indivíduo deve buscar a informação que necessita,direcionando a maneira como ele pode se 
comportar dentro do sistema. A proposta de um plano de classificação facetado que tenha as duas formas de classificação, estrutural e funcional, permite o usuário escolher a estratégia de busca que melhor lhe atenda, nesse contexto é possível, inclusive, combinar as duas estratégias, garantindo maior precisão na recuperação da informação. Este estudo propõe elaborar um modelo de plano de classificação facetado para gestão arquivística de documentos nas universidades federais do Brasil, visando auxiliar o usuário na recuperação da informação em um Sistema de Informatizado de Gestão Arquivística de Documentos (SIGAD), utilizando a teoria da classificação facetada de Ranganathan.

\section{SIGAD}

A crescente produção de documentos em formato digital levou à criação de sistemas informatizados capazes de geri-los. O SIGAD é um sistema de gestão arquivística que tem por objetivo capturar, armazenar e disponibilizar documentos arquivísticos gerenciando-os em seus ciclos de vida. Segundo o Conselho Nacional de Arquivos (CONARQ), um SIGAD é "um conjunto de procedimentos e operações técnicas que visam o controle do ciclo de vida dos documentos, desde a produção até a destinação final, seguindo os princípios da gestão arquivística de documentos e apoiado em um sistema informatizado" (BRASIL, 2011).

O SIGAD abrange as fases corrente e intermediária da gestão de documentos, mas não a guarda permanente dos mesmos, e a eliminação deve ser feita de forma controlada e de acordo com a legislação em vigor. Para controlar o ciclo de vida dos documentos são implementados o plano de classificação e da tabela de temporalidade no SIGAD. Assim, o processo de gestão documental no que se refere ao ciclo de vida dos documentos e sua destinação se torna mais simples e automático.

Para auxiliar na recuperação da informação, o SIGAD possui mecanismos de buscas que podem ser implementados através de filtros ou campos de pesquisa. A busca realizada por meio de um filtro garante a precisão da informação que será recuperada e norteia o usuário sugerindo o que pesquisar, por outro lado impede que o indivíduo realize buscas genéricas. Já a busca realizada através de campos de pesquisa dá liberdade ao usuário para pesquisar a informação da qual necessita, mas não garante a precisão do que será recuperado. Alguns tipos de SIGAD apresentam os dois tipos de busca e possibilitam combinar mais de um filtro na pesquisa, o que aumenta consideravelmente a precisão da recuperação da informação.

\section{CLASSIFICAÇÃO FACETADA}

A classificação visa agrupar documentos semelhantes em uma mesma classe, constituindo-se de uma das atividades realizada na gestão arquivística de documentos que inclui metodologias e rotinas específicas para agilizara gestão da informação. A classificação pode ser baseada em três vertentes: social, filosófica e bibliográfica.

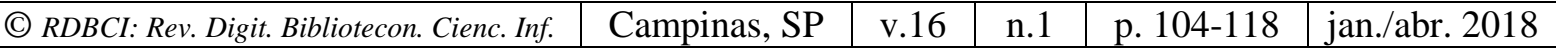


No hall dos grandes nomes da classificação está o bibliotecário e matemático Shiyali Ramamrita Ranganathan, criador da classificação facetada. Na busca em desenvolver uma técnica que pudesse fragmentar um assunto complexo, Ranganathan criou, na década de 1930, um esquema analítico que compreende a divisão de várias partes de um assunto.

Para Ranganathan, um dos problemas dos sistemas de classificação tradicionais é que a classificação dos itens só ocorre depois da definição das classes ou os termos usados.O autor objetivava partir dos itens para posteriormente, coletar e organizaras facetas que pudessem caracterizá-lo e não o contrário. Nos sistemas de classificação tradicionais os assuntos compostos devem ser elaborados antes da classificação dos documentos, já na classificação facetada, os assuntos compostos podem ser gerados durante a busca, com a combinação de termos de facetas diferentes. Dessa maneira, o sistema de classificação fica mais enxuto e ganha maior flexibilidade e especificidade, otimizando a organização, representação, busca e a recuperação da informação da informação. As facetas podem ser definidas como agrupamentos de termos que permitem descrever os itens de múltiplosângulos, perspectivas, ou atributos (HEDDEN, 2010).

A classificação baseia-se na criação de grupos com itens que possuam características recorrentes. Ranganathan constatou a existência de conceitos recorrentes em praticamente todas as áreas e para estabelecer a relação entre eles, o autor utilizou o que chamou de categorias fundamentais de noções abstratas, denominadas Personalidade, Matéria, Energia, Espaço e Tempo. As categorias fundamentais podem ser definidas como:

\footnotetext{
"Personalidade", que é o assunto ou objeto; "Matéria", que é a decomposição desse assunto ou objeto em diferentes atributos ou características (materiais, propriedades, qualidade); "Energia", que são as ações, atividades ou processos em relação ao assunto ou objeto investigado; "Espaço", que é a ambientação do assunto ou objeto, tal como seu lugar geográfico; e "Tempo", que geralmente é a data ou período histórico-contextual do objeto estudado, ou mesmo o ano de produção de tal conhecimento (MACULAN, 2011, p. 81).
}

A partir da classificação facetada é possível realizar a navegação facetada que é considerada na área de recuperação da informação uma estratégia de busca eficiente, pois permite os usuários durante a pesquisa, filtrar gradativamente os resultados,combinando os termos que ficam agrupados em cada faceta (SILVA, 2013).

Atualmente, a navegação facetada esta se popularizando, sendo usada principalmente em sites de comércio eletrônico, bibliotecas digitais e páginas amarelas (DENTON, 2003). No contexto da gestão arquivística, através do plano de navegação facetado é possível realizar a navegação facetada em um SIGAD para recuperação de documentos arquivísticos.

\section{METODOLOGIA UTILIZADA}

Com base nos conceitos apresentados e considerando o objetivo desse estudo em aliar a classificação facetada à gestão arquivística para uma melhor recuperação da informação,

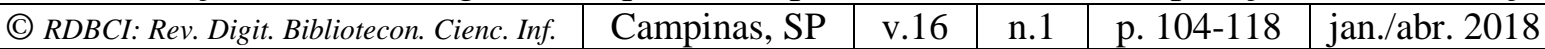


pode-se conceitualizar esse trabalho como uma pesquisa exploratória que realiza um levantamento de informações sobre o tema e identifica os fatores que determinam e contribuem para o aprofundamento do conhecimento. Por ser um tipo de pesquisa muito específica, quase sempre ela assume a forma de um estudo de caso (GIL, 2008).

Para a execução do trabalho foram seguidos os seguintes passos: 1 - Levantamento bibliográfico; 2 - Identificação do plano de classificação utilizado nas universidades federais; 3 -Criação do plano de classificação estrutural; e 4 - Criação do plano de classificação facetado em um SIGAD.

O levantamento bibliográfico consistiu numa relação das bibliografias, sejam livros, artigos de periódicos, teses, dissertações e outros materiais bibliográficos sobre planos de classificação, tipos de arranjos e classificação facetada. Essa etapa trata-se de uma seleção prévia de bibliografias ou documentos que poderão ser utilizados como referência no desenvolvimento do trabalho.

Dessa forma, foram realizadas pesquisas em bases de dados nacionais e internacionais nas áreas de Biblioteconomia e Arquivologia. Foram selecionadas as seguintes bases: a) Biblioteca Digital Brasileira de Teses e Dissertações (BDTD); b) Revista Digital de Biblioteconomia e Ciência da Informação (RDBCI); c) Biblioteca Digital de Teses e Dissertações da Universidade de São Paulo; d) Scielo Brasil, uma base eletrônica de dados científicos; e) E-prints in Library and Information Science (E-LIS); e f) Google Acadêmico. As palavras-chave utilizadas para a busca nas bases de dados foram: classificação facetada, plano de classificação e gestão de documentos. Neste caso, essas palavras poderiam estar em qualquer campo do registro, como título, resumo e palavras-chaves.

Para ter um ponto de partida, teve-se a necessidade de identificação do plano de classificação geralmente utilizado nas universidades federais. Após uma pesquisa na internet, foi identificado o plano de classificação na plataforma SIGA ${ }^{1}$, um repositório que tem por objetivo preservar, armazenar, difundir e garantir o acesso aos documentos, normas e leis referentes a gestão arquivística no Brasil.

O plano de classificação encontrado era funcional e como não foi localizado nenhum plano de classificação estrutural para universidades federais, assumiu-se que era necessário criar um para compor o plano de classificação facetado. A classificação do tipo estrutural representa os diversos níveis da divisão interna de uma organização tais como diretorias, unidades e departamentos no caso das universidades federais.

\footnotetext{
${ }^{1}$ Sistema de gestão de documentos de arquivo da administração pública federal. Tabela de temporalidade e destinação de documentos de arquivo relativos às atividades-fim das Instituições Federais de Ensino Superior IFES. Disponível em http://www.siga.arquivonacional.gov.br/images/codigos tabelas/portaria_n0922011 tabela_de temporalidade_e destinao.pdf>
}

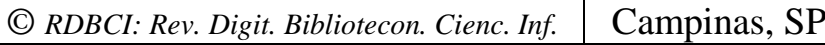

\begin{tabular}{l|l|l|l} 
v.16 & n.1 & p. $104-118$
\end{tabular}

jan./abr. 2018 
Para desenvolver o plano de classificação estrutural foram realizadas buscas nos sites de universidades e institutos federais brasileiros. Com essas pesquisas, foram recuperados organogramas das instituições que embasaram a construção da faceta estrutural e possibilitou o entendimento do funcionamento da estrutura dessas instituições e semelhanças entre elas.

Após a criação do plano de classificação estrutural e de posse do plano de classificação funcional utilizado nas universidades federais, o passo seguinte foi unir os dois planos em um SIGAD para formar o plano de classificação facetado. O SIGAD escolhido foi um sistema de gestão de repositório digital, o Tainacan.

O Tainacan é um sistema de código aberto desenvolvido a partir de uma parceria do Ministério da Cultura com a Universidade Federal de Goiás com objetivo de realizar a gestão de documentos digitais com foco na colaboração, usabilidade e experiência de usuário. Esse sistema permite a criação de vários acervos na mesma plataforma e foi escolhido principalmente pelo fato de permitir a inserção e busca a partir de uma classificação facetada.

\section{RESULTADOS ALCANÇADOS}

O plano de classificação facetado implementado no sistema Tainacan apresenta as duas facetas da organização documental, estrutural e funcional. A faceta estrutural representa a plano de classificação a partir da divisão departamental da organização, desse modo um documento gerado a partir da compra de materiais ficará armazenado na pasta do setor de compras, por exemplo. A faceta funcional dispõe os documentos a partir das suas funções, assim um documento de matrícula ficará armazenado na pasta de vida acadêmica dos alunos, por exemplo.

A faceta funcional do plano de classificação foi identificada no site SIGA, que disponibiliza o plano de classificação utilizado nas Instituições Federais de Ensino Superior. Essa faceta foi incluída no Tainacan está dividida a partir de cinco grandes funções: Ensino Superior; Pesquisa; Extensão; Educação Básica e Profissional; e Assistência Estudantil.

A faceta estrutural do plano de classificação foi desenvolvida a partir de organogramas de algumas universidades e institutos federais. Um organograma é um tipo de diagrama que representa as relações hierárquicas ou distribuição dos setores, unidades funcionais e cargos dentro de uma organização. $\mathrm{O}$ organograma representa a distribuição dos cargos e estrutura de uma entidade, nesse contexto, foram utilizados organogramas de universidades e institutos federais brasileiros para compor o plano de classificação estrutural, a pesquisa para identificar os organogramas foi realizada nos sites das seguintes instituições: Universidade Federal de Goiás - UFG; Instituto Federal Baiano - IFbaiano; Universidade Federal do Estado do Rio de Janeiro - Unirio; Universidade do Contestado - UNC; Universidade Federal do Ceará - UFC; e Universidade Tecnológica Federal do Paraná - UTFPR. A Figura 1 a seguir apresenta a faceta estrutural desenvolvida para o plano de classificação. 


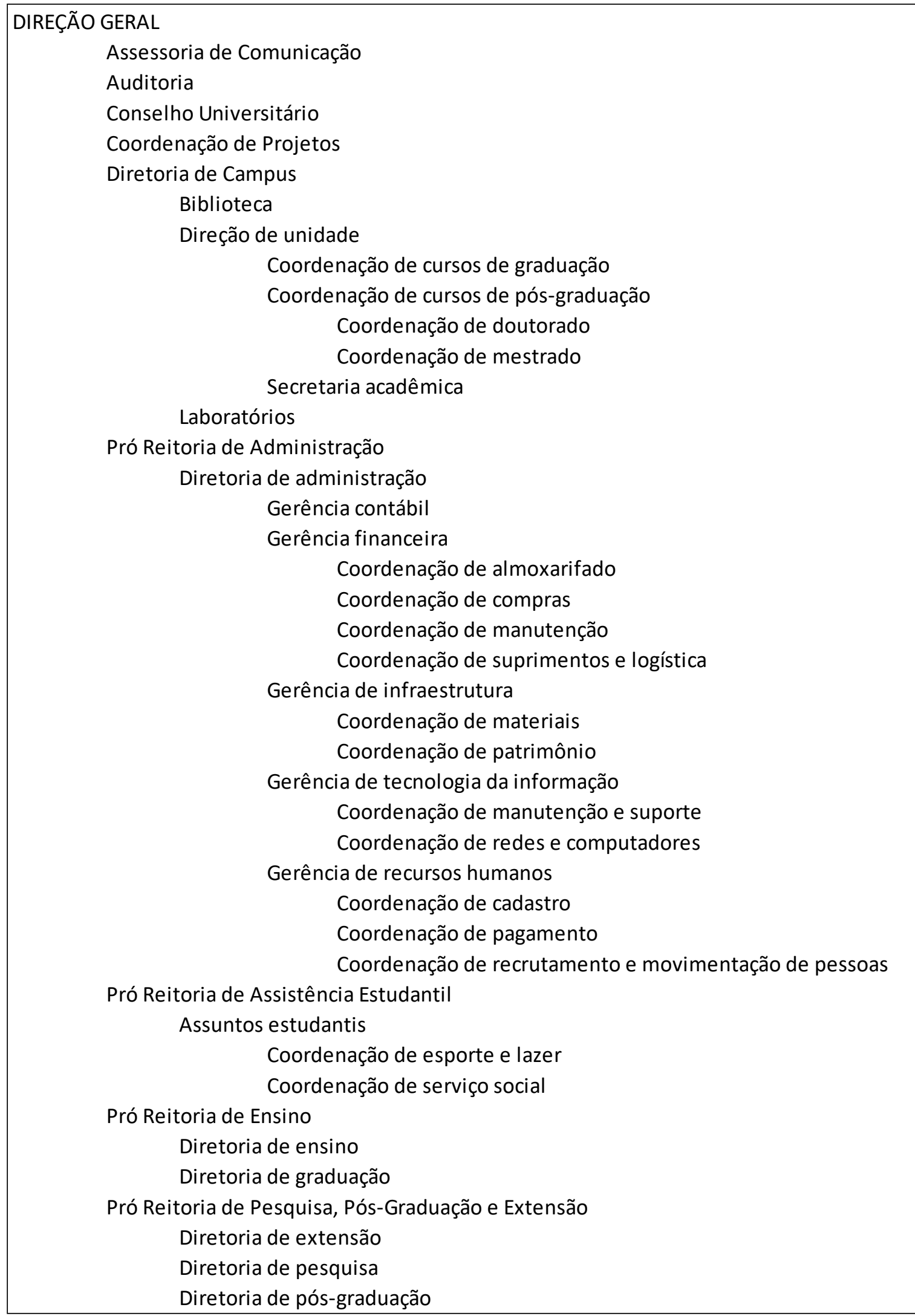

Figura 1. Plano de Classificação Estrutural

Fonte: Elaborado pelo autor 
As facetas funcionais e estruturais foram inseridas no sistema Tainacan conforme apresentado na Figura 2.

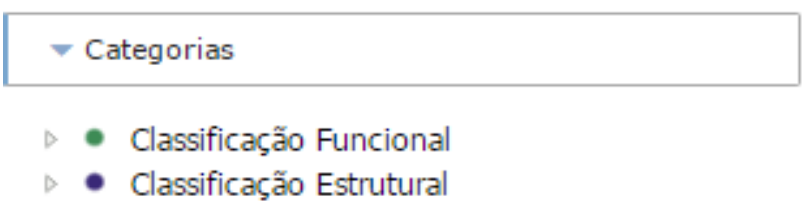

Figura 2. Facetas do Plano de Classificação Fonte: Elaborado pelo autor

A faceta funcional inserida contempla todas as funções do plano de classificação utilizado nas IFES como mostra a Figura 3 a seguir.

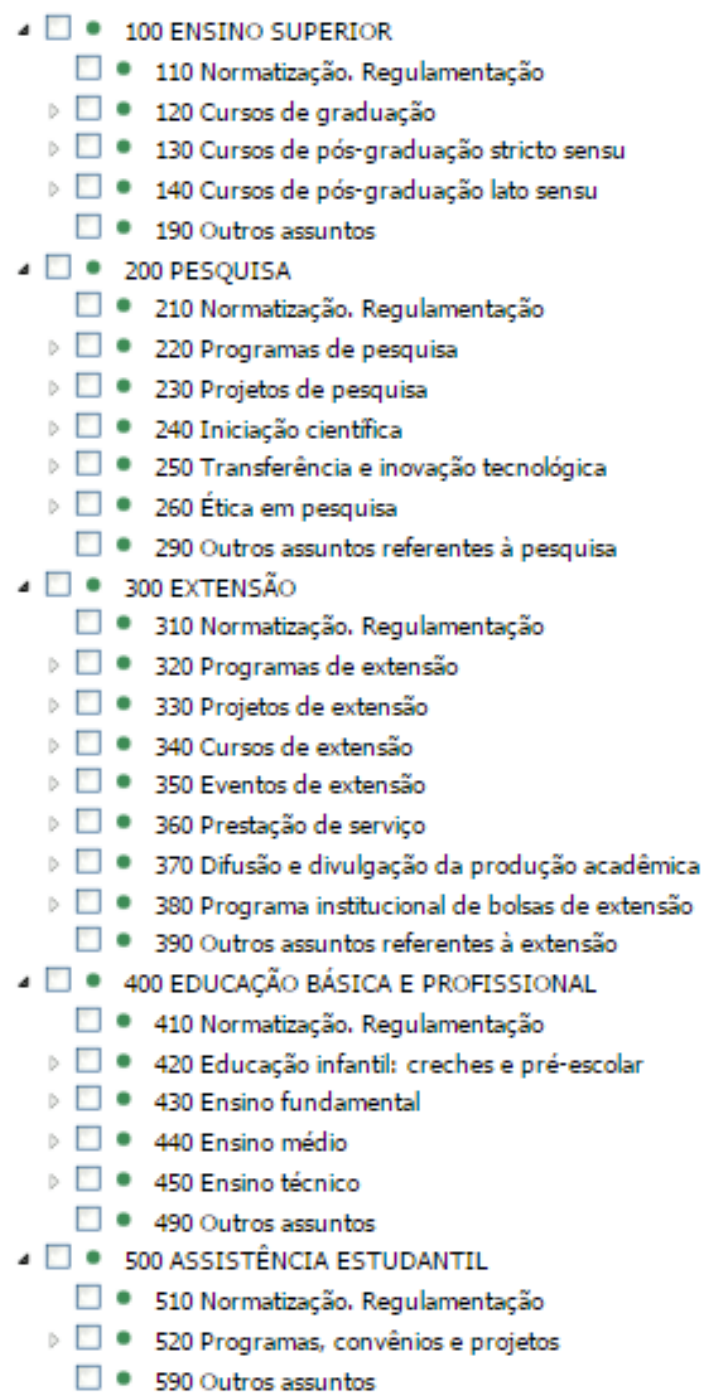

Figura 3. Funções da faceta funcional

Fonte: Elaborado pelo autor 
A faceta estrutural desenvolvida a partir dos organogramas das universidades e institutos federais foi inserida no Tainacan como mostra a figura 4 abaixo.

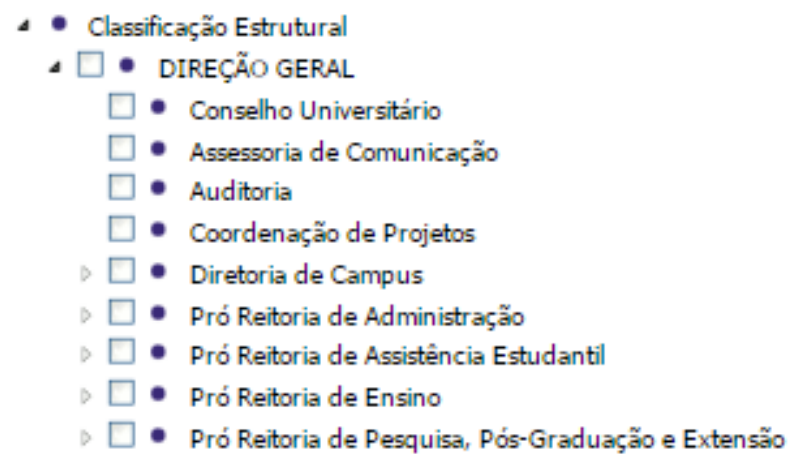

Figura 4. Faceta estrutural do plano de classificação Fonte: Elaborado pelo autor

A figura 5 a seguir apresenta o primeiro nível de segmentações dessas estruturas.

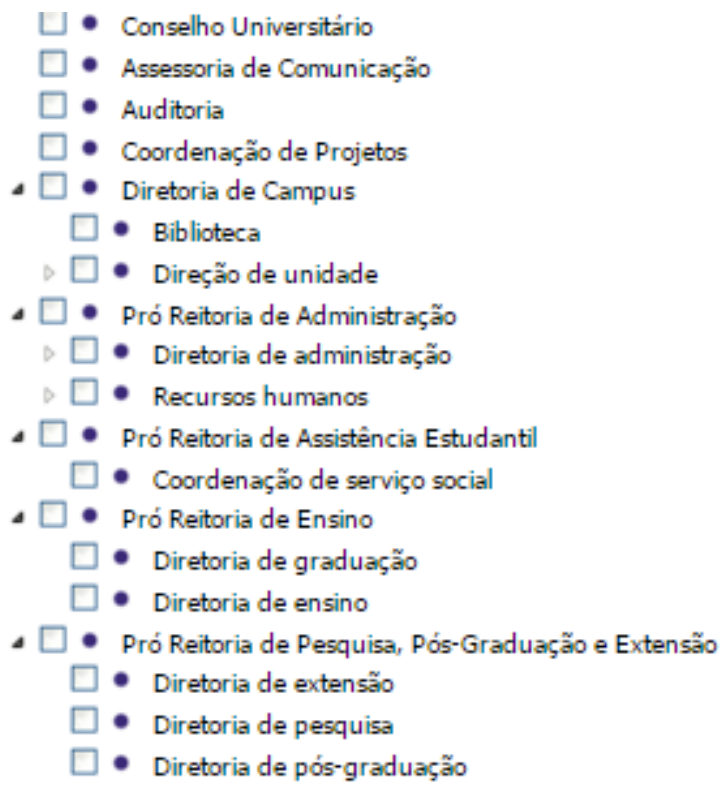

Figura 5. Divisões da faceta estrutural Fonte: Elaborado pelo autor

Utilizando as categorias de Ranganathan, a faceta estrutural do plano de classificação representa a categoria espaço. Essa faceta compreende o local onde um item pertence, o tipo estrutural representa a organização física da entidade refletida na classificação, onde as subclasses estão dispostas como os departamentos dessa entidade, representando sua organização geográfica. É importante ressaltar que essa faceta não contem os itens documentais, para não haver redundância, pois essas classes já existem na faceta funcional oriundas do plano de classificação de atividades-fim usado como base. Esse arranjo também não interfere na tabela de temporalidade, na qual os prazos de guarda continuam associados as classes da faceta funcional. 
A faceta funcional representa a categoria personalidade de Ranganathan. Essa é a categoria mais difícil de identificar, geralmente é definida por eliminação das outras, principalmente pela complexidade dessa categoria. A personalidade é tida como aquilo que se demonstra como básico e fundamental à compreensão de determinado assunto. Segundo Grolier (1962), a personalidade não possui um valor teórico, caracteriza-se como um rótulo atribuído, indispensável à existência das coisas. A função de um documento é a essência para sua utilização e recuperação na faceta do tipo funcional, sendo a característica essencial e relevante para essa classificação.

\section{CONSIDERAÇÕES FINAIS}

O objetivo desse trabalho foi desenvolver um plano de classificação facetado para gestão arquivística de documentos nas universidades federais do Brasil e implementá-lo em um SIGAD, utilizando a teoria da classificação facetada de Ranganathan para auxiliar o usuário na busca e garantir uma melhor recuperação da informação.

A faceta funcional do plano de classificação desenvolvido foi identificada no sistema que integra a documentação e normas relativas a gestão arquivística brasileira, a plataforma SIGA do Ministério da Fazenda. No caso da faceta estrutural, ela foi desenvolvida a partir dos organogramas recuperados nos sites das universidades e institutos federais brasileiras. A junção dessas duas facetas deu origem ao plano de classificação facetado.

O plano de classificação facetado elaborado para a gestão arquivística de documentos nas universidades federais possibilita a recuperação da informação de uma maneira mais eficiente, na qual o usuário pode escolher a estratégia de busca, filtrando os documentos por uma classe da faceta funcional ou estrutural ou até combinando termos de ambas facetas para restringir a pesquisa.

A partir deste trabalho podemos, futuramente, avaliar junto aos usuários da Universidade Federal de Goiás a usabilidade da classificação facetada para a busca da informação e aplicar este plano de classificação em outras universidades para avaliar a sua adequação em outras instituições e verificar se pode esse plano pode vir a se tornar um modelo para a gestão arquivística digital.

\section{REFERÊNCIAS}

ARQUIVO NACIONAL. Dicionário brasileiro de terminologia arquivística. Rio de Janeiro: Arquivo Nacional, 2005. 232 p.

BRASIL. Lei n. 8.159, de 8 de janeiro de 1991. Dispõe sobre a política nacional de arquivos públicos e privados e dá outras providências. Diário Oficial, Brasília, 9 jan. 1991.

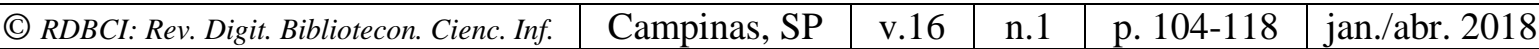


BRASIL, A. R. Q. e-ARQ Brasil: Modelo de requisitos para sistemas informatizados de gestão arquivística de documentos. Conselho Nacional de Arquivos, 2011.

CAMARGO, Ana Maria de Almeida; \& BELLOTTO, Heloísa Liberalli. Dicionário de terminologia arquivística. São Paulo: Associação dos Arquivistas Brasileiros - Núcleo Regional de São Paulo: Secretaria de Estado da Cultura. 1996.

CHOO, Chun Wei. A organização do conhecimento: como as organizações usam a informação para criar significado, construir conhecimento e tomar decisões. Senac, São Paulo, 2003.

DENTON, William. How to make a faceted classificationand put it on the web. Miskatonic University Press, nov. 2003. Disponível em: $<$ http://www.miskatonic.org/ library/facet-web- howto.html>. Acesso em: 30 ago. 2010.

HEDDEN, H. The accidental taxonomist. Medford, NJ: Information Today, 2010. 472 p.

GIL, Antonio Carlos. Como elaborar projetos de pesquisa. 4. ed. São Paulo: Atlas, 2008.

GROLIER, Eric. Tendences actuelles en matière de classifications et codifications documentaires. 1960.

MACULAN, Benildes Coura Moreira dos Santos. Taxonomia facetada navegacional: construção a partir de uma matriz categorial para trabalhos acadêmicos. 2011. 191f. Dissertação (Mestrado em Ciência da Informação) - Escola de Ciência da Informação, Universidade Federal de Minas Gerais, Belo Horizonte, 2011.

MORESI, Eduardo et al. Metodologia da pesquisa. Brasília: Universidade Católica de Brasília, v. 108, 2003.

PAES, Marilena Leite. Arquivo: teoria e prática. 3. ed.rev. ampl. Rio de Janeiro: FGV, 2002.

RANGANATHAN, Shiyali Ramamrita. Prolegomena to library classification. 3.ed. Bombay: Asia Publishing House, 1967.

RIOS, Elaine Rosa. Princípios teóricos e metodológicos para construção de planos de classificação documental: um estudo de caso: A Agência Nacional do Petróleo, Gás Natural e Biocombustíveis. 2009. Monografia (Especialização em Organização, Planejamento e Direção de Arquivos) - Universidade Federal Fluminense; Arquivo Nacional, Niterói; Rio de Janeiro, 2009.

ROBREDO, Jaime. Da ciência da informação revisitada aos sistemas humanos de

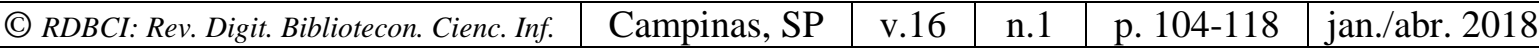


informação. Brasília, DF: Thesaurus: SSRR Informações, 2003. 245 p.

ROBREDO, Jaime. Documentação de hoje e de amanhã. Brasília, DF: Associação dos Bibliotecários do Distrito Federal, 1986. 398p.

RODRIGUES, William. Metodologia cientifica. Disponível em $<$ http://unisc.br/portal/upload/com_arquivo/metodologia_cientifica.pdf $>$ Acesso em 20/07/2016.

ROUSE, William B.; ROUSE, Sandra H. Human information seeking and design of information systems. Information Processing \& Management, v. 20, n. 1-2, p. 129-138, 1984.

SABINO, Rosimeri Ferraz; ROCHA, Fabio Gomes. Secretariado: do escriba ao web writer.Rio de Janeiro: Brasport, 2004.

SÃO PAULO (Estado). Decreto estadual no 48.897, de 27 de agosto de 2004, art. 10, parágrafo único.

SCHELLENBERG, T.R. 2005. Arquivos modernos: princípios e técnicas. Rio de Janeiro: FGV.

SILVA, Marcel Ferrante. Proposta de modelo de colaboração para catálogo web facetado. Belo Horizonte, 2013. 269f. Tese (Doutorado em Ciência da Informação)-Universidade Federal de Minas Gerais, Belo Horizonte, 2013.

SIGA, Sistema de gestão de documentos de arquivo da administração pública federal. Tabela de temporalidade e destinação de documentos de arquivo relativos às atividades-fim das Instituições Federais de Ensino Superior - IFES. Disponível em http://www.siga.arquivonacional.gov.br/images/codigos_tabelas/portaria_n0922011_tabela_d e_temporalidade_e destinao.pdf $>$. Acesso em 22/06/2016.

SOUSA, Renato Tarciso Barbosa. Alguns apontamentos sobre a classificação de documentos de arquivo. Brazilian Journal of Information Science, v. 8, n. 1-2, 2014.

SOUSA, Renato Tarciso Barbosa de. A classificação como função matricial do que fazer arquivístico. Arquivística: temas contemporâneos: classificação, preservação digital, gestão do conhecimento. Brasília: SENAC, p. 115-163, 2007. 